\title{
The effect of in-service education on nurses' preference for the ventrogluteal site in intramuscular injection implementation
}

\author{
Deniz Öztürk ${ }^{1}$ \\ Zehra Göçmen Baykara ${ }^{2}$ \\ Ayişe Karadağ ${ }^{3}$ \\ Evrim Eyikara ${ }^{4}$
}

\begin{abstract}
Purpose: This study conducted to determine the effect of in-service education on nurses' preference for the ventrogluteal site in intramuscular injection implementation.

Method and materials: In this intervention study, the sample comprised 45 clinic nurses, where intramuscular injection practice is frequently applied. In-service education was conducted with regards to applying intramuscular injection to the ventrogluteal site. In the content of the planned education, the transmission of theoretical information on the subject, the demonstration on the manikin and video were included. Then, the nurses carried out the intramuscular injection implementation on the manikin under the supervision of the researchers. The data were collected at 2014 through the use of the "Nurses' VG Site Injection Preference Status Form". The data collection form was applied before the in-service education and two months after the in-service education.

Results: The results showed that $71.11 \%$ of the nurses did not receive education on intramuscular injection implementation in the ventrogluteal site in basic nursing education. In basic nursing education, $84.44 \%$ of the nurses used the dorsogluteal site and $22.22 \%$ the ventrogluteal site for intramuscular injection. The number of intramuscular injection implementations of the nurses in the ventrogluteal site was increased from 2.18 to 9.04 after the in-service education $(p=0.001)$. The nurses stated that, they felt more comfortable during ventrogluteal injection implementation, after the in-service education,

Conclusion: After the in-service education of the nurses, it was determined that the number of IMI implementations in the ventrogluteal site increased.
\end{abstract}

Keywords: In-service education; injection; intramuscular; nursing; ventrogluteal site.

\footnotetext{
$1 \mathrm{RN}, \mathrm{PhD}$, Assistant Professor, Başkent University, Faculty of Health Sciences, Nursing Department, deniz genc@hotmail.com

${ }^{2}$ RN, PhD, Instructor, Gazi University, Faculty of Health Science Department of Nursing, gocmenzehra@yahoo.com

${ }^{3}$ RN, PhD, Professor, Koç University, Faculty of Nursing, ayisekaradag@gmail.com

${ }^{4}$ RN, Research Assistant, Gazi University, Faculty of Health Science Department of Nursing, evrimeyikara@gmail.com
} 
Öztürk, D., Göçmen Baykara, Z., Karadağ, A., \& Eyikara, E. (2017). The effect of in-service education on nurses' preference for the ventrogluteal site in intramuscular injection implementation. Journal of Human Sciences, 14(4), 4199-4205. doi:10.14687/jhs.v14i4.5009

\section{Introduction}

An average of 12 billion parenteral drug implementations are performed worldwide per year (Gittens and Bunnell, 2009). One of the most common parenteral drug implementations is intramuscular injection (IMI) (Kaya et al., 2015). IMI can be applied to different sites of the body where muscle tissue is involved. However, the site that nurses use frequently is the dorsogluteal (DG) site (Güneş et al., 2009; Kaya et al., 2015). In fact, in the DG site, the sciatic nerve passes close to the injection site, and it is known that the anatomical location of the sciatic nerve differs from person to person. For this reason, IMI is reported to be safer in the ventrogluteal (VG) site than in the DG site to prevent possible complications (Ogston-Tuck, 2014).

The VG site comprises gluteus medius and gluteus minimus muscles. The VG site is safe for use during injections because its muscle tissue is thick, and it is remote from large blood vessels and nerves. For these reasons, serious injuries are unlikely to occur as a result of injections into the VG site. Because less subcutaneous fat tissue is in the VG site, the possibility of injecting into subcutaneous tissue is low (Berman et al., 2016: 797-798). In addition, complications, such as fibrosis, nerve damage, abscess, tissue necrosis, muscle contraction, gangrene and pain, are less likely to develop in the VG site. For this reason, it is stated that this site can easily be used in infants, children or adults for the injection of irritating and oily solutions (DeLaune and Ladner, 2011: 780; Wilkinson et al., 2016: 650).

Although the use of the VG site for IMI has been proposed for many years, the frequency of use among nurses is low (Cocoman and Murray, 2010; Gülnar and Çalışkan, 2014; Walsh and Brophy, 2011). In the research with 264 nurses that Walsh and Brophy (2011) conducted, it was reported that although nurses were aware of the possible complications of injecting into the DG site, they preferred the DG site primarily. In the same research, nurses stated that they feel comfortable when they identify the injection site and prioritize knowledge from the existing literature later. Cocoman and Murray (2010) stated that nurses knew the importance of the VG site but did not prefer the site due to difficulties in identifying the site anatomically. They also emphasized that nurses should be informed about the current literature to increase their usage rate of this site. In the survey with 283 nurses that Gülnar and Çalışkan (2014) conducted, it was reported that $85.9 \%$ of the nurses used the DG site most frequently, whereas $34 \%$ of the nurses did not have knowledge about the VG site injection, and this issue was not emphasized very well in their basic education.

Engstrom et al. (2000) stated the most important reasons why nurses did not prefer the VG site for IMI: Education programs did not comprise sufficient injecting implementations in the VG site, and nurses cannot identify the VG site. In another study that Tuğrul and Denat (2014) conducted with 85 nurses, $48.2 \%$ of the nurses stated they always used the DG site during their IMI implementations, and 38.8\% stated they never used the VG site. In the same study, it was determined that $72.9 \%$ of the nurses did not have sufficient knowledge related to the VG site, and $44.7 \%$ were worried, as they had not used this site at all. Gülnar and Çalışkan (2014) stated that the majority of the nurses prefer the DG site and did not use the VG site because they were not accustomed to it. As can be understood from the concerned literature, reasons such as the relatively difficult detection of the VG site and the VG site's low usage rate may cause nurses to be reluctant to use this site (Floyd and Meyer, 2007; Wynaden et al., 2006). In this context, it can be argued that in IMI implementations, it is difficult for nurses to adapt to injecting into an area to which they are not accustomed (Alannah and Floyd, 2007).

The above mentioned studies demonstrate that nurses need in-service education, which will contribute to their preference for the VG site, a safer and recommended site for IMI implementation. Although the advantages of using the VG site during IMI implementation are explained in the existing literature, a limited number of studies will enable nurses to prefer the VG site and increase their knowledge on this subject. It is thought that in-service education that will enable nurses to prefer the VG site in IMI will contribute to this field. 
Öztürk, D., Göçmen Baykara, Z., Karadağ, A., \& Eyikara, E. (2017). The effect of in-service education on nurses' preference for the ventrogluteal site in intramuscular injection implementation. Journal of Human Sciences, 14(4), 4199-4205. doi:10.14687/ihs.v14i4.5009

\section{Purpose}

The research was conducted to determine the effect of in-service education on nurses' preference for the VG site in IMI implementation.

\section{Method and material}

\subsection{Population and sample selection}

The research was conducted with nurses working in emergency department, general surgery, urology, cardiovascular surgery, plastic surgery, orthopedics and anesthesia reanimation clinics, where IMI implementation is frequently applied at a 1037-bed university hospital in a metropolis in Turkey. The total number of nurses working in these clinics was 95, and the implementation was performed with 45 nurses volunteering to participate in the research. In this research, the participation rate of the nurses was $47 \%$.

\subsection{Type of study}

An intervention design was used in this study.

\subsection{Data collection tools}

The data were obtained using the "Nurses' VG Site Injection Preference Status Form" that the researchers developed based on the literature. The form contained questions addressing the nurses' gender, age, education status, clinical experience, the site they use for IMI, the IMI implementation of nurses in the VG site, number of injection implementation, opinions of nurses about IMI implementation in the VG site etc.

\subsection{Procedures}

The "Nurses' VG Site Injection Preference Status Form" was applied to nurses who volunteered to participate in the research after they were informed about the research. Then, trainings were conducted for nurses to apply IMI to the VG site. The in-service education content consisted of three parts. The first part of the education covered theoretical information about the anatomy of the VG site, the injection site of the VG site, the size of the needle to be used, the amount of the drug to be administered and so on. Then, the nurses viewed a video showing IMI implementation in the VG site as performed on a real patient, and IMI implementation was demonstrated on a manikin. Videos shared with nurses after demonstrating. Following practical training with theoretical knowledge, the nurses engaged in IMI implementation in the VG site on the manikin. The nurses performed their implementations under the supervision of the researchers. In addition, all of the questions were answered during the implementation, and it was ensured that the site was personally determined and that the injections were made. The in-service education program featured two sessions lasting three hours in total on the same day, with both theoretical knowledge and implementation covered.

During the two months following the completion of the in-service education, the nurses were supported in performing IMIs into the VG site in their clinics. The researchers made weekly visits to the clinics and answered questions about the nurses' IMI implementations. In addition, counseling was provided to the nurses who needed it and demanded it by phone. Two months after the completion of the in-service education, the 'Nurses' VG Site Injection Preference Status Form' was applied for the second time.

\subsection{Limitations of study}

The limitedness of the research is constituted by the fact that it was conducted in a university hospital and with a limited number of nurses. Researchers were not together with nurses in clinical practice during IMI implementations. 
Öztürk, D., Göçmen Baykara, Z., Karadağ, A., \& Eyikara, E. (2017). The effect of in-service education on nurses' preference for the ventrogluteal site in intramuscular injection implementation. Journal of Human Sciences, 14(4), 4199-4205. doi:10.14687/jhs.v14i4.5009

\subsection{Research ethics}

Ethical committee permission from the Gazi University Clinical Research Ethics Committee (Application 25901600-1734) and written permission from the Chief Physician of the Health Research and Application Centre at Gazi University were obtained for the research. Verbal permission to participate in the research was also obtained from the nurses.

\subsection{Evaluation of data}

Data were evaluated using SPSS (17.0) software (SPSS, Inc., 2007). The Shapiro-Wilk test was used because of the unit numbers during the investigation of the normal distribution of variables. A chi-square analysis was applied when the relations between groups of nominal variables were examined. Fisher's exact test was used when the expected values in the cells on the $2 \mathrm{x} 2$ tables did not have sufficient volumes, and the Pearson chi-square analysis was applied on $\mathrm{RxC}$ tables with the help of a Monte Carlo simulation. While examining the variance between the two dependent variables, the Wilcoxon test was used because the variables do not come from the normal distribution. While interpreting the results, 0.05 was used as the significance level; when it was $\mathrm{p}<0.05$, it was stated that a significant relation existed, and when it was $\mathrm{p}>0.05$, it was stated that no significant relation existed.

\section{Results}

A total of $100 \%$ of the nurses were female, $71.11 \%$ of the nurses who participated in the research each have a bachelor's degree. $57.78 \%$ of them each have more than six years of clinical training. A total of $71.11 \%$ of the nurses stated that they did not receive education on IMI into the VG site in their basic nursing education. A total of $84.44 \%$ of the nurses stated that they used the DG site for IMI and $22.22 \%$ the VG site in their basic nursing education. The most significant reasons why nurses do not prefer IMI implementation in the VG site are that, in nursing education, injection into the VG site was not taught (60\%), and detection of the DG site is easy $(48.89 \%)$. The average age of the nurses who participated in the research was $\bar{X}=31.66 \pm 7.93$ (min: 22 , max: 54) (Table 1).

Table 1. Descriptive characteristics of nurses

\begin{tabular}{llcc}
\hline Characteristics & Categories & $\mathbf{n}$ & $\mathbf{\%}$ \\
\hline \multirow{3}{*}{ Last completed education program } & Undergraduate formal education & 32 & 71.11 \\
& Undergraduate remote & 5 & 11.11 \\
& Medical vocational high school & 3 & 6.67 \\
& Associate degree & 2 & 4.44 \\
& Post graduate & 3 & 6.67 \\
\hline Total clinical training in nursing & $0-5$ years & 19 & 42.22 \\
& 6 years or more & 26 & 57.78 \\
\hline Education on IMI implementation in the VG site & Did not receive & 32 & 71.11 \\
in nursing education & Receive & 13 & 28.89 \\
\hline & DG & 38 & 84.44 \\
Site used for IMI in basic nursing education & Deltoid & 18 & 40 \\
& Vastus lateralis & 14 & 31.11 \\
& Rectus femoris & 14 & 31.11 \\
& VG & 10 & 22.22 \\
\hline & DG & 35 & 77.78 \\
Site frequently preferred for IMI implementation & VG & 8 & 17.78 \\
& Rectus femoris & 6 & 13.33 \\
& Deltoid & 5 & 11.11 \\
& Vastus lateralis & 3 & 6.67 \\
\hline
\end{tabular}


Öztürk, D., Göçmen Baykara, Z., Karadağ, A., \& Eyikara, E. (2017). The effect of in-service education on nurses' preference for the ventrogluteal site in intramuscular injection implementation. Journal of Human Sciences, 14(4), 4199-4205. doi:10.14687/jhs.v14i4.5009

Reasons for not preferring the VG site*

It was not taught how to inject into

60

the VG site in nursing education.

Detection of the DG site is easy.

Patients do not prefer injection 6

48.89

implementation in the VG site.

Age average

$\overline{\mathrm{X}}=31.66 \pm 7.93$ (min: 22, max: 54)

*Nurses signed more than one option

Whereas the number of IMI implementations of nurses in the VG site was $\bar{X}=2.18 \pm 5.14$ before education, it was $\bar{X}=9.04 \pm 16.19$ after education. The number of IMI implementations of nurses in the VG site showed a statistically significant increase after education $(p=0.001)$ (Table 2).

Table 2. Statuses of IMI implementation in the VG site for nurses before and after education

\begin{tabular}{lccc}
\hline Number of injection implementation & Mean & SS & $p^{*}$ \\
\hline Before education & 2.18 & 5.14 & $0.001^{* *}$ \\
After education & 9.04 & 16.19 & \\
\hline$*$ Wilcoxon test & & & \\
$* * \mathrm{p}<0.05$ & & &
\end{tabular}

Before education, $40 \%$ of the nurses stated they would be excited to apply IMI, but this rate decreased to $22.22 \%$ after education. In addition, $31.11 \%$ of the nurses stated they could easily apply IMI to the VG site before education, and this ratio increased to $53.33 \%$ after education. A total of $22.22 \%$ of the nurses before education and $55.56 \%$ after education stated they applied IMI implementation in the VG site (Table 3).

Table 3. Opinions of nurses about IMI implementation in the VG site

\begin{tabular}{lcccc}
\hline Statements of nurses & \multicolumn{2}{l}{ Before education } & \multicolumn{2}{l}{ After education } \\
\cline { 2 - 5 } & $\mathbf{n}$ & $\mathbf{0}$ & $\mathbf{n}$ & $\mathbf{\%}$ \\
\hline I get excited when I apply IMI to the VG site & 18 & 40 & 10 & 22.22 \\
\hline I comfortably apply IMI to the VG site & 14 & 31.11 & 24 & 53.33 \\
\hline I applied IMI to the VG site & 10 & 22.22 & 25 & 55.56
\end{tabular}

\section{Discussion}

This research was conducted to determine the effect of in-service education on nurses' preference for the VG site in IMI implementation. Forty-five nurses participated in this study, which was conducted as intervention research.

It was determined that most of the nurses who participated in the study had been working in nursing for at least six years $(57.78 \%)$ and that most of the nurses $(71.11 \%)$ did not receive education on IMI implementation in the VG site during their nursing education. In Turkey, IMI skill is generally taught in the first year of undergraduate programs and within the scope of the Fundamentals of Nursing course. Until recently, textbooks indicated that the sites used in IMI implementations are generally the DG site, VG site, deltoid muscle and vastus lateralis muscle, and their implementation patterns were detailed (Kozier et al., 2000: 784-785; Ramont and Niedringhaus, 2004: 517-518). However, in the current literature, information about how the sciatic nerve is close to the injection site in the DG site and how its position changes from person to person is strongly indicated. For this reason, it has been emphasized since the beginning of the 2000s that the DG site should not be used in IMI implementation (Berman et al., 2016: 798; DeLaune and Ladner, 2011: 780; Wilkinson et al., 2016: 650). However, the fact that nurses already perform IMI implementations in particular sites affects nurses' preference for the VG site in their IMI implementations. The majority of the nurses participating in the research each have a bachelor's degree, and when their age average is considered, they make up a relatively young group. 
Öztürk, D., Göçmen Baykara, Z., Karadağ, A., \& Eyikara, E. (2017). The effect of in-service education on nurses' preference for the ventrogluteal site in intramuscular injection implementation. Journal of Human Sciences, 14(4), 4199-4205. doi:10.14687/jhs.v14i4.5009

The knowledge of the preference for the VG site in IMI implementations in Turkey has entered the main course books for the past decade. For this reason, nurses often prefer the DG site for IMI in their practices.

Nurses participating in the research indicated that they preferred the DG site in a large proportion $(77.78 \%)$ and the VG site in a low proportion (17.78\%). Our findings run parallel with the literature. Floyd and Meyer (2007) stated that $99 \%$ of nurses use the DG muscle, whereas only $9 \%$ percent of nurses use the VG site for the purpose of IMI. In the study that Güneş et al. (2009) ( $\mathrm{n}=110$ ) conducted, $60 \%$ of the nurses stated that they have always applied IMI to the DG site, and $78.2 \%$ have never used the VG site. Similarly, Tuğrul and Denat (2014) reported in their study $(n=85)$ that $48.2 \%$ of the nurses use the DG site at all times, and $38.8 \%$ never use the VG site. In another study that Gülnar and Çalsskan (2014) conducted, $85.9 \%$ of the nurses use the DG site, and $63.3 \%$ of the nurses do not use the VG site at all. The results of this study reveal that nurses do not prefer the VG site primarily for IMI that in-service education is needed on this issue. It is necessary to prefer IMI implementation in the VG site not alternatively but primarily.

In our research, although the mean number of IMI implementations of the nurses was 2.18 \pm 5.14 before the education, it was calculated as $9.04 \pm 16.19$ after the training $(p=0.001)$. Gülnar and Özveren (2016) determined in their study $(\mathrm{n}=81)$ that the nurses were given a planned training program on IMI and that the ratio of the nurses' usage of the VG site increased after the training. For this reason, nurses' knowledge and skills about IMI should be updated with planned in-service education. Evidence-based implementations cannot be conducted unless the nurses' knowledge and skills are updated (Cocoman and Murray, 2010). The fact that an increase in the IMI implementation averages of the nurses in the VG site was detected in our study suggests that the nurses are interested in updating their knowledge and skills. For this reason, it is important that the nurses are informed about the current literature, the benefits of the training are given attention and the nurses' awareness of the subject is increased by organizing continuous in-service education.

The excitement ratio of the nurses participating in the study when applying IMI to the VG site after in-service education decreased from $40 \%$ to $22.22 \%$. In addition, the ratio of nurses who said they could easily apply IMI to the VG site increased from $31.11 \%$ to $53.33 \%$. Greenway (2004) stated that the nurses' knowledge and skills in the use of VG sites are not adequate and that they lack the confidence to carry out the skills unaided. Therefore, they are reluctant to use this site. Alannah and Floyd (2007) stated that nurses have difficulty adapting to a different method they are not used to. The reason given for this was that the VG site is difficult to identify and that the use of the DG site in the nursing literature was recommended for a period of time starting in the 1960s. Walsh and Brophy (2011) reported that when the nurses $(\mathrm{n}=264)$ select the site of IMI implementation, $85.2 \%$ of them select the site with which they are comfortable, whereas $15.2 \%$ of them act in parallel with the literature. Although the current literature recommends using the VG site in IMI implementation, nurses prefer injection implementation in this site at a lower level. Any kind of change can cause some resistance and anxiety in people. Especially in invasive interventions, it is important that nurses feel safe and comfortable when they perform implementations and that they do not have any anxiety. However, it is necessary that nurses keep pace with the new and current literature and that they learn new information/implementations (Walsh and Brophy, 2011). Knowledge, skills and experience need to be increased for a skill to be implemented safely.

\section{Conclusion and recommendations}

According to this study, most of the nurses did not gain proficiency in preferring the VG site for IMI and performing implementations in this site during their basic education. For this reason, they do not prefer the VG site in their professional implementations. Following the conducted inservice education, it was determined that the number of injections that the nurses administered in the VG site increased and that the nurses felt more comfortable when administering injections in 
Öztürk, D., Göçmen Baykara, Z., Karadağ, A., \& Eyikara, E. (2017). The effect of in-service education on nurses' preference for the ventrogluteal site in intramuscular injection implementation. Journal of Human Sciences, 14(4), 4199-4205. doi:10.14687/jhs.v14i4.5009

this site. There was also a decrease in their excitement statuses. In line with the research results, it was suggested that the in-service education for the nurses should be done in larger groups and that the education should be repeated periodically.

\section{References}

Alannah, M., \& Floyd S. (2007). Intramuscular injections - what's best practice? why is there such a gap between what is taught in nursing schools about the best sites end technique for intramuscular injections and what actually happens in practice? two nurses decided to find out. Kai Tiaki: Nursing New Zealand, $7(1): 25-31$.

Berman, A., Snyder, S., \& Frandsen, G. (2016). Kozier \& Erb's Fundamentals of nursing concepts, process, and practice. 10th ed. Pearson; pp. 797-798.

Cocoman, A., \& Murray, J. (2010). Recognizing the evidence and changing practice on injection sites. British Journal of Nursing, 19(18): 1170-1174. https://doi.org/10.12968/bjon.2010.19.18.79050

DeLaune, S.C., \& Ladner, P.K. (2011). Fundamentals of nursing standards \& practice. 4th ed. Delmar Cengage Learning; pp. 780.

Engstrom, J.L., Giglio, N.N., Takacs, S.M., Ellis, M.C., \& Cherwenka, D.I. (2000). Procedures used to prepare and administer intramuscular injections: a study of infertility nurses. Journal of Obstetric, Gynecologic, and Neonatal Nursing, 29(2): 159-168. http://dx.doi.org/10.1111/j.1552-6909.2000.tb02036.x

Floyd, S., \& Meyer, A. (2007). Intramuscular injections -what is best practice? Why is there such a gap between what is taught in nursing schools about the best sites end technique for intramuscular injections and what actually happens in practice? Two nurses decided to find out. Nursing New Zealand, 13(6): 20-22.

Gittens, G., \& Bunnell, T. (2009). Skin disinfection and its efficacy before administering injections. Nursing Standard, 23(39): 42-44. https://doi.org/10.7748/ns2009.06.23.39.42.c7039

Greenway, K. (2004). Using the ventrogluteal site for intramuscular injection. Nursing Standard, 18(25): 39-42. https://doi.org/10.7748/ns2004.03.18.25.39.c3560

Gülnar, E., \& Çalışkan, N. (2014). Determination of knowledge level of nurses regarding intramuscular injection administration to ventrogluteal site introduction. Dokuz. Ellül Üniversitesi Hemsirelik Yükesekokulu Elektronik Dergisi, 7(2): 70-77.

Gülnar, E., \& Özveren, H. (2016). An evaluation of the effectiveness of a planned training program for nurses on administering intramuscular injections into the ventrogluteal site. Nurse Education Today, 36: 360-363. https://doi.org/10.1016/j.nedt.2015.09.001

Güneş, Ü.Y., Zaybak, A., Biçici, B., \& Çevik, K. (2009). The examination of the procedures regarding to intramuscular injection used by the nurses. Atatürk Üniversitesi Hemsirelik Yüksekokulu Dergisi, 12(4): 8490.

Kaya, N., Salmaslıŏlu, A., Terzi, B., Turan, N., \& Acunaş, B. (2015). The reliability of site determination methods in ventrogluteal area injection: A cross-sectional study. International journal of nursing studies, 52(1): $355-360$.

Kozier, B., Erb, G., Berman, A.J., \& Burke, K. (2000). Fundamentals of nursing concepts, process, and practice. 6th ed. Multimedia edition; pp. 784-785.

Ogston-Tuck, S. (2014). Intramuscular injection technique: an evidence-based approach. Nursing Standard, 29(4): 52-59. https://doi.org/10.7748/ns.29.4.52.e9183

Ramont, R.P., \& Niedringhaus, D.M. (2004). Fundamental nursing care. 6th ed. Upper Saddle River NJ: Pearson Prentice Hall. pp. 517-518.

SPSS Inc (2007). SPSS Statistics Base 17.0 User Guides. SPSS Inc., Chicago, IL.

Tuğrul, E., \& Denat, Y. (2014). Nurses' knowledge, opinion and practices regarding to injection practices in ventrogluteal site. Dokuz. Eylül Üniversitesi Hemsirelik Yüksekokulu Elektronik Dergisi, 7(4): 275-284.

Walsh, L., \& Brophy, K. (2011). Staff nurses' sites of choice for administering intramuscular injections to adult patients in the acute care setting. Journal of Advanced Nursing, 67(5): 1034-1040. http://dx.doi.org/10.1111/j.1365-2648.2010.05572.x

Wilkinson, J.M., Treas, L.S., Barnett, K., \& Smith, M.H. (2016). Fundamentals of nursing. 3th ed. F. A. Davis Company; pp. 650.

Wynaden, D., Landsborough, I., McGowan, S., Baigmohamad, Z., Finn, M., \& Pennebaker, D. (2006). Best practice guidelines for the administration of intramuscular injections in the mental health setting. International Journal of Mental Health Nursing, 15(3): 195-200. http://dx.doi.org/10.1111/j.14470349.2006.00423.x 